\title{
Investigating reconstructed inflows and pathogen infection patterns between low-relief and high-relief subtropical oyster reefs
}

\author{
Benjamin D. Walther ${ }^{*}$ (D), Paxton T. Bachand, Andrew Hinson, Colin A. O’Donnell and \\ Jeffrey W. Turner
}

Department of Life Sciences, Texas A\&M University - Corpus Christi, Corpus Christi, Texas78412

${ }^{*}$ Corresponding author: E-mail: benjamin.walther@tamucc.edu

(Received 28 January 2020; Revised 20 May 2020; Accepted 14 June 2020)

\begin{abstract}
Flood and drought events cause significant freshwater inflow fluctuations in estuaries, potentially leading to physiological stress and altered abundances of pathogens such as Vibrio vulnificus and Perkinsus marinus in oysters. To assess the effects of freshwater pulses to oyster reefs in subtropical estuaries in Texas, this study accomplished two goals: 1) reconstructed a reef-specific history of freshwater pulses through shell stable isotope analysis, 2) quantified the abundance of $V$. vulnificus and P. marinus through culture-dependent and culture-independent microbiology analyses. Oysters from a low-relief and high-relief reef experienced similar fluctuations in shell isotopes, indicating similar ranges of past environmental conditions. $V$. vulnificus and $P$. marinus were detected throughout the study but the abundance of these microorganisms was not correlated with environmental parameters or one another. Importantly, the $P$. marinus infection intensity was always lower at the high-relief reef, which suggests that high-relief reefs may experience lower infection frequencies.
\end{abstract}

Keywords: Oysters; estuaries; stable isotopes; Vibrio; Dermo

\section{Introduction}

The purpose of the project was to assess how variation in reconstructed freshwater inflow affects the abundance of pathogens in oysters from low-relief and high-relief reefs in subtropical estuaries in Texas. Punctuated flood events, such as those during Hurricane Harvey, bring large amounts of freshwater to oyster reefs which can have profound implications for oyster physiological stress and loading of harmful bacteria and parasites (Froelich et al., 2012; Pollack et al., 2012). Oysters are subject to colonization by $V$. vulnificus which is a naturally occurring marine bacterium and one of the deadliest human pathogens (Strom \& Paranjpye, 2000). Oysters are also subject to infection by the Dermo-causing parasite P. marinus which can cause significant mortality of oysters. Assessing links between inflows and $V$. vulnificus and P. marinus requires time series of salinity variations at the reef scale, which are often unavailable from instrumental monitoring. Fortunately, oyster shells themselves naturally record inflow

The words natural and restored were changed to low-relief and high-relief throughout this article. A corrigendum notice detailing the changes has been issued. 
fluctuations via stable isotope ratios of oxygen and carbon that are incorporated into shell growth increments (Walther \& Rowley, 2013). Pairing this individual record of inflow stress with assessments of $V$. vulnificus and $P$. marinus abundance is a potential way to identify the effects of inflow variation on oyster health.

\section{Objective}

This study had two primary goals: 1) reconstruct a reef-specific history of inflow fluctuations through shell stable isotope analysis, and 2) quantify the abundance of $V$. vulnificus and P. marinus through culture-dependent and culture-independent microbiology analyses. This work was carried out in two locations with different reef types in Texas: the high-relief Shellbank Reef in Copano Bay (Latitude N $28^{\circ} 6^{\prime} 43^{\prime \prime}$, Longitude W 97 $9^{\prime} 6^{\prime \prime}$ ) and a low-relief reef in St. Charles Bay (Latitude N 28 $08^{\prime} 22^{\prime}$, Longitude W $\left.96^{\circ} 58^{\prime} 11^{\prime}\right)$. The study aimed to compare inflow histories and pathogen infection patterns between low-relief and high-relief reefs to assess if pathogen susceptibility differs among these reef types.

\section{Methods}

A total of 40 oysters (Crassostrea virginica) were collected by dredge from two reefs on five dates (04/08/2019, 04/29/2019, 05/29/2019, 07/09/2019, and 07/29/2019, 4 oysters collected per site each date). Vibrio analyses were not performed on samples collected on 05/29/2019 because of a temporary lack of available facilities, however Vibrio were analyzed from the remaining four dates. Environmental parameters (temperature, salinity, $\mathrm{pH}$, and dissolved oxygen) were measured at 0.5 meters depth with a handheld YSI 556 sonde (YSI Inc., Yellow Springs, OH). Oysters were stored in a cooler between $10-15^{\circ} \mathrm{C}$ and returned to the lab where they were rinsed/cleaned with filter-sterilized seawater and shucked with flame-sterilized tools. Temperature variation during transit was monitored using a Kestrel Drop D1 (Kestrel Meters, Boothwyn, PA) and oysters were processed within four hours of collection. To quantify P. marinus abundance, a $5 \mathrm{~mm}^{2}$ section of mantle tissue was incubated for two weeks at room temperature in fluid thioglycollate media and the infection intensity was assigned a numerical value ranging from 0 (no infection) to 5 (heavy infection) (Ray, 1952). Remaining tissue was used to quantify $V$. vulnificus abundance in a two-step process: selective culture of presumptive $V$. vulnifucus isolates using V. vulnificus X-gal (VVX) agar (Griffitt \& Grimes, 2013) followed by species confirmation of selected isolates by polymerase chain reaction (PCR) using primers targeting the species-specific $v v h A$ gene (Kaysner \& DePaola, 2004). Six oyster shells (three from each reef), collected 5/29/2019, were processed to extract 5-14 subsamples of carbonate ( $0.3 \mathrm{mg}$ powder each) from sectioned oyster shells for $\delta^{18} \mathrm{O}$ and $\delta^{13} \mathrm{C}$ isotope analyses following methods available online at http://dx.doi.org/10.17504/ protocols.io.bbd7ii9n. Additional methods are provided in the Supplementary Information.

\section{Results}

The environmental parameters (temperature, salinity, $\mathrm{pH}$, and dissolved oxygen) varied minimally over the study (Figure 1). The abundance of presumptive V. vulnificus varied moderately over the study, ranging from not detectable to 9,066 colony forming units (CFU) $\mathrm{mL}^{-1}$ (Figure 2). A species-specific PCR test determined that fewer than half of the isolates (54/120 or 45\%) possessed the species-specific $v v h A$ gene target. The infection intensity of $P$. marinus also varied minimally over the study, ranging from 0 (not detectable) to 1.67 (light infection; Figure 3). There were no obvious differences in isotope patterns between Shellbank Reef and St. Charles Bay. One-way repeated measures analyses of variance did not identify statistically significant differences in values of either $\delta^{18} \mathrm{O}(\mathrm{F}(13,5)=1.05, p=0.41)$ or $\delta^{13} \mathrm{C}(\mathrm{F}$ $(13,5)=1.0, p=0.44)$ among shells (Figure 4$)$. Oyster isotope data are available in full online at Walther and Hinson (2020). Environmental and pathogen data are available in full online at Turner (2020). Additional results are discussed in Walther et al. (2019). 

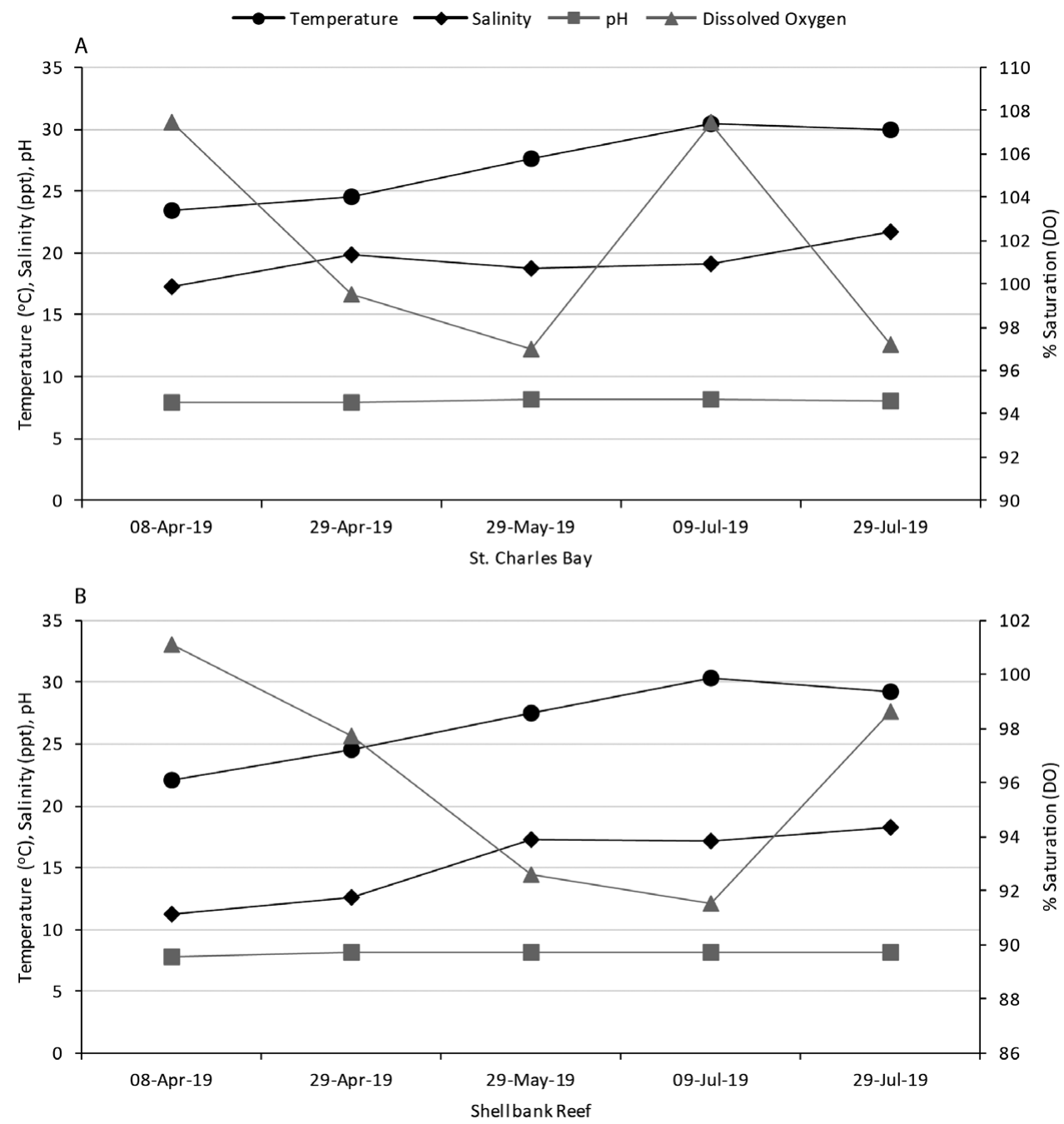

Figure 1. The variation in temperature $\left({ }^{\circ} \mathrm{C}\right)$, salinity (ppt), $\mathrm{pH}$, and dissolved oxygen (\% saturation) recorded over the three month study period in (A) low-relief St. Charles Bay and (B) high-relief Shellbank Reef.

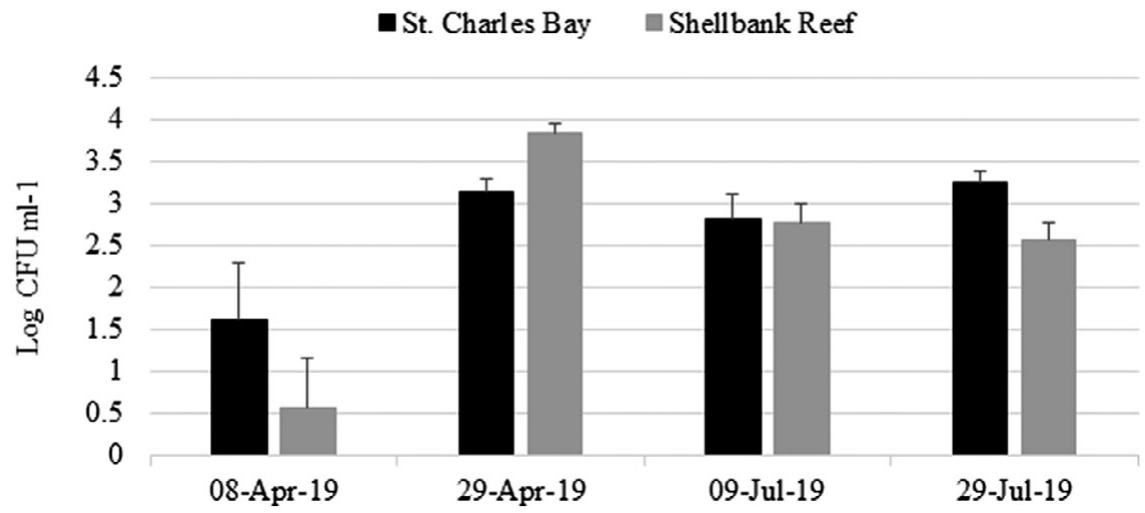

Figure 2. The variation in the log-transformed abundance of presumptive $V$. vulnificus (CFU mL ${ }^{-1}$ oyster homogenate) over the three month study period in high-relief Shellbank Reef and low-relief St. Charles Bay. Columns show the average abundance $(\mathrm{N}=4$ oysters per site) and error bars show the standard error. 
- St. Charles Bay $\square$ Shellbank Reef

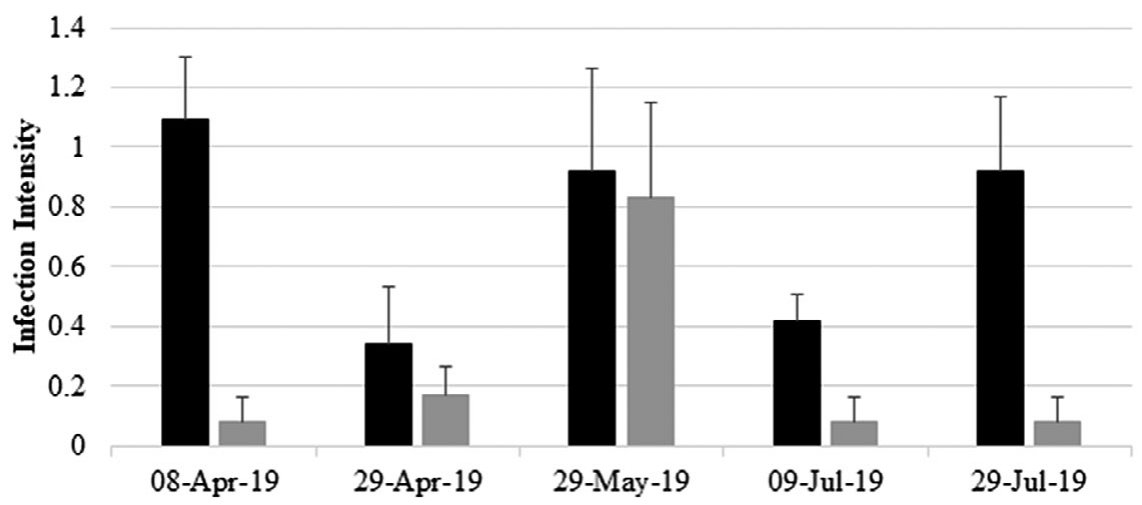

Figure 3. Variation in the infection intensity of $P$. marinus over the three month study period in high-relief Shellbank Reef and lowrelief St. Charles Bay. Columns show the average infection intensity ( $N=4$ oysters per site) and error bars show the standard error.
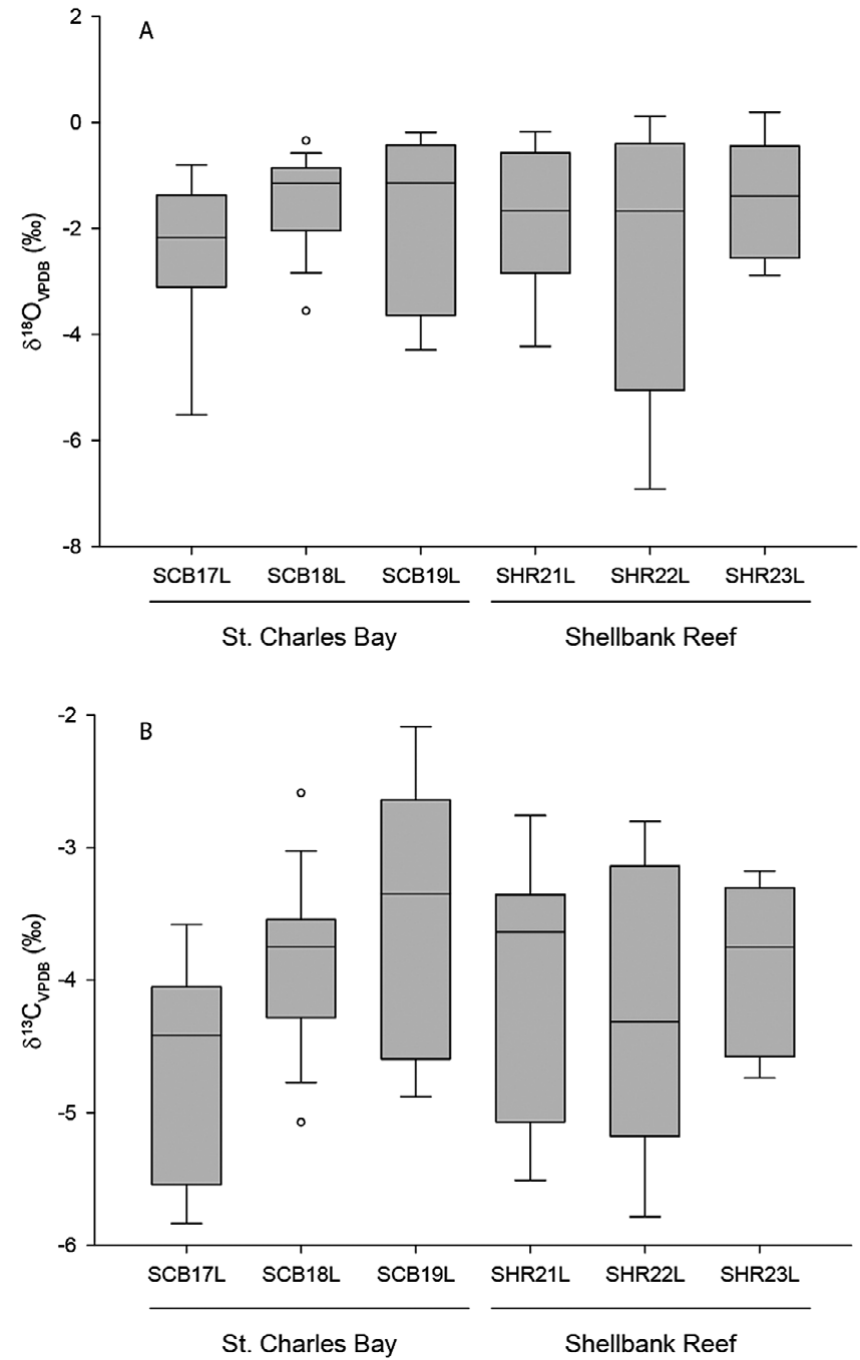

Figure 4. Boxplots depicting variations in $(A) \delta^{18} \mathrm{O}$ and $(\mathrm{B}) \delta^{13} \mathrm{C}$ values within individual shells from low-relief St. Charles Bay and high-relief Shellbank Reef. 


\section{Discussion}

This work did not find major or consistently identifiable differences in either environmentallydependent isotope reconstructions or pathogen prevalence. This result may have been due to the relatively similar environmental conditions found at both reef sites. Fewer than half of the isolates tested were confirmed as $V$. vulnificus, indicating that the media was semi-selective rather than selective (i.e., it permitted the growth of non-target species) at the incubation temperature of $30^{\circ} \mathrm{C}$. Alternative and more accurate methods such as colony blot hybridization and real-time PCR are available but the cost and labor of these methods was prohibitive in this study.

\section{Conclusions}

This study attempted to assess how two distinct reefs responded to freshwater intrusion. The shell isotopes indicated that both reefs experienced similar inflow fluctuations over the lifetimes of the oysters. Thus, this study at least afforded a comparison of a low-relief reef versus a high-relief reef that experienced similar environmental conditions. The abundance of $V$. vulnificus and the infection intensity of $P$. marinus served as proxies for monitoring changes in oyster microbiota. The abundance of V. vulnificus was not significantly different between reefs but the Dermo infection intensity was often lower in the high-relief reef. This decreased infection intensity may relate to the reef height as high-relief reefs may experience less sedimentation and stress.

Acknowledgements. The authors thank Robert Duke and Jay Tarkington from the Texas A\&M University-Corpus Christi (TAMU-CC) Center for Coastal Studies for their assistance with field sampling. Shell stable isotope analyses were conducted at the University of California Davis Stable Isotope Facility by Richard Doucette. Rosario Martinez at the Coastal Bend Bays and Estuaries Program provided assistance with project management and oversight. The authors also thank Dr. Jennifer Beseres Pollack and her Research Associate Natasha Breaux (TAMU-CC Harte Research Institute) for conducting the Dermo analysis. The authors assert that all procedures contributing to this work comply with the ethical standards of the relevant national and institutional guides on the care and use of laboratory animals. Oysters were collected with permission under Texas Parks and Wildlife Department Scientific Research Permit No. SPR-0117-20.

Author Contributions. BDW and JWT conceived and designed the study. PTB, CAO, and AH conducted field sampling. PTB and CAO conducted molecular analyses. AH processed shells for analyses. BDW, PTB, AH, CAO and JWT analyzed data and wrote the article.

Funding Information. This work was funded by the Texas Commission on Environmental Quality and the Coastal Bend Bays and Estuaries Program (CBBEP Contract \#1920).

Data Availability Statement. Shell isotope data are available online at: https://doi.org/10.6084/m9.figshare.11608347 Environmental and pathogen data are available online at: https://doi.org/10.6084/m9.figshare.11733426.v1

Conflict of Interest. BDW, PTB, AH, CAO, and JWT declare none.

Supplementary Materials. To view supplementary material for this article, please visit http://dx.doi.org/10.1017/exp.2020.28.

\section{References}

Froelich, B. A., Williams, T. C., Noble, R. T., \& Oliver, J. D. (2012). Apparent loss of Vibrio vulnificus from North Carolina oysters coincides with a drought-induced increase in salinity. Applied and Environmental Microbiology, 78, 3885-3889.

Griffitt, K. J., \& Grimes, D. J. (2013). A novel agar formulation for isolation and direct enumeration of Vibrio vulnificus from oyster tissue. Journal of Microbiological Methods, 94, 98-102.

Kaysner, C. A., \& DePaola, A. (2004). Bacteriological analytical manual, chapter 9. In Vibrio. Federal Drug Administration.

Pollack, J. B., Cleveland, A., Palmer, T. A., Reisinger, A. S., \& Montagna, P. A. (2012). A restoration suitability index model for the eastern oyster (Crassostrea virginica) in the Mission-Aransas estuary, TX, USA. PLoS ONE, 7, e40839.

Ray, S. M. (1952). A culture technique for the diagnosis of infections with Dermocystidium marinum Mackin, Owen, and Collier in oysters. Science, 116, 360-361.

Strom, M. S., \& Paranjpye, R. N. (2000). Epidemiology and pathogenesis of Vibrio vulnificus. Microbes and Infection, 2, $177-188$.

Turner, J. (2020). Oyster environmental and pathogen data. figshare. https://doi.org/10.6084/m9.figshare.11733426.v1 
Walther, B., \& Hinson, A. (2020). Oyster shell isotope data from Texas. figshare. https://doi.org/10.6084/m9.figshare.11608347 Walther, B. D., \& Rowley, J. L. (2013). Drought and flood signals in subtropical estuaries recorded by stable isotope ratios in bivalve shells. Estuarine, Coastal and Shelf Science, 133, 235-243. http://dx.doi.org/10.1016/j.ecss.2013.08.032.

Walther, B. D., Turner, J., Bachand, P., O’Donnell, C. and Hinson, A. (2019). Oyster flood tracker project: Reconstructing inflows to reefs and effects on Vibrio vulnificus and Perkinsus marinus abundance. Final Report to Coastal Bend Bays and Estuaries Program. Project number: 1920.

Cite this article: Walther BD, Bachand PT, Hinson A, O’Donnell CA, Turner JW (2020). Investigating reconstructed inflows and pathogen infection patterns between low-relief and high-relief subtropical oyster reefs Experimental Results, 1, e23, 1-9. https://doi.org/10.1017/exp.2020.28 


\title{
Peer Reviews
}

\section{Reviewing editor: Dr. Yonghoon Kim}

West Chester University of Pennsylvania, Dept. of Earth and Sapce Sciences, 217 Merion Science Center, West Chester, Pennsylvania, United States, 19383

This article has been accepted because it is deemed to be scientifically sound, has the correct controls, has appropriate methodology and is statistically valid, and met required revisions.

doi:10.1017/exp.2020.28.pr1

\section{Review 1: Investigating salinity fluctuations and pathogen infection patterns between natural and restored subtropical oyster reefs}

Reviewer: Prof. Brett Froelich

Date of review: 11 February 2020

\begin{abstract}
(c) The Author(s), 2020. Published by Cambridge University Press This is an Open Access article, distributed under the terms of the Creative Commons Attribution licence (http://creativecommons.org/licenses/by/4.0/), which permits unrestricted re-use, distribution, and reproduction in any medium, provided the original work is properly cited.
\end{abstract}

Conflict of interest statement. Reviewer declares none

Comments to the Author: The authors collected four oysters each from two sites over five days. Quantity of $\mathrm{V}$ vulnificus, and $\mathrm{P}$ marinus was measured, along with environmental parameters. The analysis seems incomplete, as it is unclear if the environmental parameters had any correction with vibrio abundance. Furthermore, it is unclear if the vibrio abundance data was presented as is, or after correcting for the PCR confirmation. Both of these can be completed without extra field or lab work. No explanation is provided why only four of the five samples have vibrio data. Finally, 6 oysters is often the minimum for performing this type of work, but four is still acceptable. L86: Forgot to replace X and Y with values. Figure 2: Does this figure consider the PCR data confirming VV?

\section{Score Card}

Presentation

5.0

Is the article written in clear and proper English? (30\%)

Is the data presented in the most useful manner? (40\%)

Does the paper cite relevant and related articles appropriately? (30\%)

Context

5.0

Does the title suitably represent the article? (25\%)

Does the abstract correctly embody the content of the article? (25\%)

Does the introduction give appropriate context? (25\%)

Is the objective of the experiment clearly defined? (25\%) 
Analysis

3.2

Does the discussion adequately interpret the results presented? (40\%)

Is the conclusion consistent with the results and discussion? (40\%)

Are the limitations of the experiment as well as the contributions of the experiment clearly outlined? (20\%) 


\title{
Review 2: Investigating salinity fluctuations and pathogen infection patterns between natural and restored subtropical oyster reefs
}

\author{
Reviewer: Prof. Jeong Eun Ahn ${ }^{1,2}$ \\ ${ }^{1}$ Rowan University, Civil and Environmental Engineering , 201 Mullica Hill Road, Glassboro, United States, 08028-1700 \\ ${ }^{2}$ New York University, New York, United States, 10012-1126
}

Date of review: 19 March 2020

\begin{abstract}
(C) The Author(s), 2020. Published by Cambridge University Press This is an Open Access article, distributed under the terms of the Creative Commons Attribution licence (http://creativecommons.org/licenses/by/4.0/), which permits unrestricted re-use, distribution, and reproduction in any medium, provided the original work is properly cited.
\end{abstract}

Conflict of interest statement. Reviewer declares none.

Comments to the Author: In the manuscript entitled "Investigating salinity fluctuations and pathogen infection patterns between nature and restored subtropical oyster reefs," the authors demonstrate that the abundance of the pathogen and environmental conditions at nature and restored subtropical oyster reefs that have similar environmental conditions including salinity fluctuations. In the opinion of this reviewer, I suggest modifying a few details. Title: I would suggest redefining the title. L 24: This study did not investigate the significant salinity fluctuations in estuaries. L 37 - 38: This study did not investigate the impacts of variations of salinity on the abundance of the pathogen in oysters, and please revise this sentence to better work with the results, and include the comparison between nature and restored oyster reefs. Figures 1-3: Please indicate nature and restored oyster reefs in captions. Figure 1: Are Temperature, salinity, $\mathrm{pH}$, and Dissolved Oxygen values depth-averaged or measured at a specific point (i.e., bottom, surface)? Figure 2: where is data collected on May 29, 2019?

\section{Score Card}

\section{Presentation}

5.0

Is the article written in clear and proper English? (30\%)

Is the data presented in the most useful manner? (40\%)

Does the paper cite relevant and related articles appropriately? (30\%)
Does the title suitably represent the article? (25\%)

Does the abstract correctly embody the content of the article? (25\%)

Does the introduction give appropriate context? (25\%)

Is the objective of the experiment clearly defined? (25\%)
Analysis
Does the discussion adequately interpret the results presented? (40\%)

Is the conclusion consistent with the results and discussion? (40\%)

Are the limitations of the experiment as well as the contributions of the experiment clearly outlined? $(20 \%)$ 